\title{
Implementasi Algoritma Genetika untuk Optimasi Penjadwalan Mata Kuliah
}

\author{
Agung Nugroho ${ }^{1}$, Wowon Priatna ${ }^{2}$, Ikhsan Romli ${ }^{3}$ \\ Sekolah Tinggi Teknologi Pelita Bangsa, Teknik Informatika, Indonesia ${ }^{1,2,3}$ \\ Email: agung@pelitabangsa.ac.id ${ }^{1}$, wowon@pelitabangsa.ac.id ${ }^{2}$, ikhsan.romli@pelitabangsa.ac.id $^{3}$
}

\begin{abstract}
Abstrak
Penjadwalan merupakan masalah kombinasional yang memiliki batasan-batasan kondisi yang harus dipenuhi, oleh karena itu hal ini menjadi pekerjaan rumit yang harus diselesaikan dengan cepat, tepat dan akurat. Ketersediaan ruangan, kapasitas kelas, ketersediaan dosen dan jumlah mahasiswa merupakan batasan mutlak yang harus dipenuhi dalam menyusun jadwal. Proses penjadwalan dengan batasanbatasan tersebut membutuhkan ketelitian agar mendapatkan jadwal yang sesuai, namun prosesnya memakan waktu dan terkadang masih terjadi bentrok antar jadwal. Untuk mengatasi masalah tersebut, diperlukan suatu metode untuk melakukan optimasi proses penjadwalan. Pengoptimalan masalah tersebut biasanya melibatkan suatu algoritma. Algoritma yang telah banyak digunakan dalam masalah penjadwalan adalah Algoritma Genetika. Algoritma ini berhasil mengungguli Algoritma yang lain dengan fitness rata-rata paling tinggi. Pada penelitian ini, telah dibuat aplikasi penjadwalan mata kuliah menggunakan Algoritma Genetika untuk menyelesaikan masalah tersebut.
\end{abstract}

\section{Keywords - optimation, scheduling, genetic algorithm}

\section{Latar Belakang}

Penjadwalan mata kuliah merupakan rutinitas yang dilakukan prodi stiap awal semester. Proses pembuatan jadwal pada umumnya dilakukan menggunakan spreadsheet, dengan menyusun tabel-tabel data draft jadwal. Cara seperti ini membutuhkan waktu yang lama karena komponen penyusun jadwal sangatlah kompleks, sehingga kurang efektif dan efisien.

Permasalahan utama dalam proses menyusun jadwal perkuliahan adalah bagaimana cara mengkombinasikan antara dosen, mata kuliah, ruang, waktu, dan kelas dengan baik tanpa terjadi saling bentrok. Walaupun sebetulnya masalah tersebut dapat diatasi dengan cara konvensional yaitu secara manual tetapi cara tersebut memerlukan waktu yang panjang serta harus dilakukan dengan teliti dan fokus agar hasil penyusunan jadwalnya tidak terjadi bentrok.

Hal-hal yang biasanya disiasati oleh penyusun jadwal dalam menyusun adalah mengelompokkan data berupa waktu kesediaan dosen serta mata kuliah yang sanggup diampu. Kemudian, mata kuliah yang paling sedikit diminati untuk diampu oleh para dosen akan didahulukan untuk dijadwalkan. Meskipun penyusun sudah melakukan dengan trik seperti itu, waktu yang dibutuhkan untuk menyelesaikan pekerjaan tersebut bisa sampai berjam-jam bahkan bisa berhari-hari.

Pada setiap komponen penyusun jadwal tersebut terdapat banyak aturan dan batasan-batasan yang telah ditentukan, oleh karena itu diperlukan sistem penjadwalan mata kuliah yang bisa dilakukan secara otomatis dengan bantuan komputer yang dapat membuat jadwal dengan cepat, akuran dan efisien dengan tetap memperhatikan aturan-aturan tersebut.

Penjadwalan mata kuliah merupakan rutinitas yang dilakukan prodi stiap awal semester. Proses pembuatan jadwal pada umumnya dilakukan menggunakan spreadsheet, dengan menyusun tabel-tabel data draft jadwal. Cara seperti ini membutuhkan waktu yang lama karena komponen penyusun jadwal sangatlah kompleks, sehingga kurang efektif dan efisien.

Permasalahan utama dalam proses menyusun jadwal perkuliahan adalah bagaimana cara mengkombinasikan antara dosen, mata kuliah, ruang, waktu, dan kelas dengan baik tanpa terjadi saling bentrok. Walaupun sebetulnya masalah tersebut dapat diatasi dengan cara 
konvensional yaitu secara manual tetapi cara tersebut memerlukan waktu yang panjang serta harus dilakukan dengan teliti dan fokus agar hasil penyusunan jadwalnya tidak terjadi bentrok.

Hal-hal yang biasanya disiasati oleh penyusun jadwal dalam menyusun adalah mengelompokkan data berupa waktu kesediaan dosen serta mata kuliah yang sanggup diampu. Kemudian, mata kuliah yang paling sedikit diminati untuk diampu oleh para dosen akan didahulukan untuk dijadwalkan. Meskipun penyusun sudah melakukan dengan trik seperti itu, waktu yang dibutuhkan untuk menyelesaikan pekerjaan tersebut bisa sampai berjam-jam bahkan bisa berhari-hari.

Pada setiap komponen penyusun jadwal tersebut terdapat banyak aturan dan batasan-batasan yang telah ditentukan, oleh karena itu diperlukan sistem penjadwalan mata kuliah yang bisa dilakukan secara otomatis dengan bantuan komputer yang dapat membuat jadwal dengan cepat, akuran dan efisien dengan tetap memperhatikan aturan-aturan tersebut.

Ada banyak penelitian tentang jenis algoritma optimasi yang dapat diterapkan untuk mengoptimalkan dalam penyusunan jadwal perkuliahan secara otomatis, antara lain Algoritma Particle Swarm Optimization [1], Algoritma Genetika [2]. Dua metode yang sering digunakan oleh peneliti sebelumnya yaitu Algoritma Genetika dan Algoritma Particle Swarm Optimization (PSO). Akan tetapi Marbun, dkk. mengatakan bahwa hasil komparasi terkait kinerja antara kedua jenis algoritma tersebut telah terbukti bahwa fitness rata-rata dari Algoritma Genetika berhasil mengungguli Algoritma PSO [3].

Algoritma genetika merupakan suatu teknik pencarian solusi dengan menggunakan prinsip seleksi alam[4]. Algoritma genetika bekerja dengan memilih himpunan penyelesaian yang direpresentasikan dengan kromosom, yang disebut dengan populasi. Solusi diambil dari dari populasi yang ada untuk membentuk populasi baru berdasarkan nilai fitness untuk mencari solusi yang terbaik.

Penelitian ini menggunakan kasus program studi Teknik Informatika Sekolah Tinggi teknologi Pelita Bangsa, Bekasi.

\section{Metode}

\subsection{Penjadwalan}

Penjadwalan adalah kegiatan yang berkaitan dengan membangun jaringan waktu dengan satu atau lebih sumber daya dari organisasi tersebut. Sumber daya yang dimaksud bisa berupa perlengkapan, peralatan, fasilitas, dan aktivitas manusia[5]. Sedangkan menurut Pinedo[6] Penjadwalan selalu berhubungan dengan pengalokasian sumber daya yang ada pada jangka waktu tertentu. Kegiatan penjadwalan disebabkan karena adanya beberapa pekerjaan yang dikerjakan secara bersamaan, sedangkan sumber daya yang dimiliki terbatas.

\subsection{Algoritma Genetika}

Algoritma genetik adalah suatu algoritma pencarian yang berbasis pada mekanisme seleksi alam dan genetika. Algoritma genetika merupakan salah satu algoritma yang sangat tepat digunakan dalam menyelesaikan masalah optimasi kompleks, yang sulit dilakukan oleh metode konvensional [7].

\section{Struktur Dasar Algoritma Genetika.}

1. Membangkitkan populasi awal

Populasi awal ini dibangkitkan secara random sehingga didapatkan solusi awal. Populasi itu sendiri terdiri atas sejumlah kromosom yang merepresentasikan solusi yang diinginkan.

2. Membentuk generasi baru

Untuk membentuk generasi baru, digunakan operator reproduksi/seleksi, crossover dan mutasi. Proses ini dilakukan berulang-ulang sehingga didapatkan jumlah kromosom yang cukup untuk membentuk generasi baru di mana generasi baru ini merupakan representasi dari solusi baru. Generasi baru ini dikenal dengan istilah anak (offspring).

3. Evaluasi solusi

Pada tiap generasi, kromosom akan melalui proses evaluasi dengan menggunakan alat ukur yang dinamakan fitness. Nilai fitness suatu kromosom menggambarkan kualitas kromosom dalam populasi tersebut. Proses ini akan mengevaluasi setiap populasi dengan menghitung nilai fitness setiap kromosom dan mengevaluasinya sampai terpenuhi kriteria berhenti.

\subsection{Analisa Masalah}

Saat ini proses penjadwalan matakuliah di prodi Teknik Informatika STT Pelita Bangsa masih dilakukan dengan cara manual, sehingga dalam proses pembuatan jadwal masih sering terjadi jadwal kelas bentrok, baik pada waktu maupun ruang kelas yang digunakan.

Oleh karena itu, untuk mengatasi permasalah tersebut akan lebih baik apabila dalam proses penjadwalan mata kuliah dilakukan dengan bantuan kecerdasan buatan sehingga dapat meminimalisir terjadinya bentrok jadwal atau ketidak sesuaian dengan penjadwalan. Dengan 
adanya kecerdasan buatan, proses penjadwalan dapat dilakukan secara otomatis sehingga dapat menghemat waktu dan dapat memaksimalkan proses penjadwalan.

\subsection{Elemen Penyusun Jadwal}

Proses penjadwalan mata kuliah tersusun dari beberapa elemen utama seperti kelas, mata kuliah, ruang, waktu, dan dosen. Masing-masing elemen memiliki karakteristik yang berbeda dalam proses pembuatan jadwal kuliah.

Kelas merupakan sekumpulan mahasiswa yang mengikuti perkuliahan pada mata kuliah tertentu. Di prodi Teknik Informatika STT Pelita Bangsa, kelas ditentukan berdasarkan angkatan masuk. Setiap angkatan dibagi beberapa kelas dengan ketentuan jumlah maksimal kelas adalah 40 mahasiswa. Setiap kelas dalam Penjadwalan mata kuliah, akan ditentukan paket mata kuliahnya di tiap-tiap semester. contoh daftar kelas yang ada dapat dilihat pada table 1.

Tabel 1. Daftar kelas

\begin{tabular}{lllll}
\hline No & Kelas & Jumlah & Program & Semester \\
\hline 1 & TI.17.A.1 & 50 & Pagi & 2 \\
2 & TI.17.A.2 & 50 & Pagi & 2 \\
3 & TI.17.B.1 & 40 & Malam & 2 \\
4 & TI.17.B.2 & 40 & Malam & 2 \\
5 & TI.17.B.3 & 35 & Malam & 2 \\
\hline
\end{tabular}

Mata kuliah merupakan data sebaran daftar mata kuliah yang ditentukan di tiap-tiap semester berdasarkan kurikulum yang berlaku. Table 2 adalah contoh sebaran mata kuliah berdasarkan paket semester.

Dosen merupakan tenaga pengajar yang mengampu mata kuliah pada kelas dan semester tertentu seusai bidang keahliannya. Table 3 adalah contoh data dosen yang ada.

Ruang merupakan tempat penyelenggaraan perkuliahan. Ruang yang tersedia pada prodi Teknik Informatika STT Pelita Bangsa semuanya dapat digunakan pada semua jam mata kuliah yang ada. Kapasitas ruang yang tersedia sebagian besar sama, akan tetapi ada beberapa ruang yang memiliki kapasitas yang berbeda. Table 4 adalah contoh data ruang yang ada.

Tabel 2. Contoh daftar mata kuliah

\begin{tabular}{lllll}
\hline No & Kode & Mata kuliah & sks & Semester \\
\hline 1 & MMU1 & Pendidikan Agama & 2 & 1 \\
& 01 & & & \\
2 & $\begin{array}{l}\text { MMU1 } \\
02\end{array}$ & Bahasa Inggris 1 & 2 & 1 \\
& 02 & & \\
\hline
\end{tabular}

\begin{tabular}{|c|c|c|c|c|}
\hline 3 & KPI201 & Kalkulus & 3 & 1 \\
\hline 4 & KPI202 & $\begin{array}{l}\text { Algorithma Dan } \\
\text { Pemrograman } 1\end{array}$ & 2 & 1 \\
\hline 5 & KPI203 & $\begin{array}{l}\text { Prak Algoritma Dan } \\
\text { Pemrograman } 1\end{array}$ & 2 & 1 \\
\hline 6 & KPL303 & $\begin{array}{l}\text { Pengantar } \\
\text { Teknologi Informasi }\end{array}$ & 3 & 1 \\
\hline 7 & $\begin{array}{l}\text { MMU1 } \\
03\end{array}$ & Bahasa Inggris 2 & 2 & 2 \\
\hline 8 & KPI204 & Aljabar Linier & 3 & 2 \\
\hline 9 & KPI205 & Logika Informatika & 3 & 2 \\
\hline 10 & KPI206 & $\begin{array}{l}\text { Pendidikan } \\
\text { Pancasila \& } \\
\text { Kewarganegaraan }\end{array}$ & 2 & 2 \\
\hline 11 & KPI207 & $\begin{array}{l}\text { Algorithma Dan } \\
\text { Pemrograman } 2\end{array}$ & 2 & 2 \\
\hline 12 & KPI208 & $\begin{array}{l}\text { Pratikum } \\
\text { Algorithma Dan } \\
\text { Pemrograman } 2\end{array}$ & 2 & 2 \\
\hline
\end{tabular}

Tabel 3. Daftar dosen

\begin{tabular}{lll}
\hline No & NIDN & Nama \\
\hline 1 & 0415058205 & Agung Nugroho, M.Kom \\
2 & 0408107502 & Donny Maulana. S.Kom, M.MSi \\
3 & 0403049102 & Andriani, S.ST., MT \\
4 & 0415088207 & Wahyu Hadikristanto, \\
& & S.Kom.,M.Kom. \\
5 & 0417118103 & Wiyanto, S.Kom., M.Kom. \\
6 & 0426018003 & Aswan Supriyadi Sunge S.E, M.Kom \\
7 & 0427075905 & Ir. Nanang Tedi Kurniadi M.T \\
8 & 0420118405 & A. YUDI PERMANA, S.Kom, M.Kom \\
9 & 0413058603 & Ikhsan Romli, S.Si., M.Sc \\
10 & 0426078401 & Elkin Rilvani, S.Kom, M.M \\
\hline
\end{tabular}

Tabel 4. Daftar ruang

\begin{tabular}{lll}
\hline No & Ruang & Kapasitas \\
\hline 1 & 201 & 50 \\
2 & 202 & 50 \\
3 & 203 & 50 \\
4 & 204 & 50 \\
5 & 205 & 50 \\
\hline
\end{tabular}

Waktu merupakan kombinasi dari jam dan hari yang digunakan dalam penyelenggaraan perkuliahan. Pada prodi Teknik Informatika STT Pelita Bangsa, perkuliahan dilaksanakan selama 5 hari dalam seminggu, yaitu mulai hari senin sampai dengan hari jumat. Setiap hari dibagi menjad 7 sesi kecuali hari jumat menjadi 6 sesi. Table 5 adalah urutan waktu yang digunakan.

Program Studi Teknik Informatika

Universitas Prima Indonesia (UNPRI) Medan 
Tabel 5. Waktu sesi perkuliahan

\begin{tabular}{lll}
\hline Sesi & Jam Mulai & Jam Selesai \\
\hline 1 & 08.30 & 10.00 \\
2 & 10.00 & 11.30 \\
3 & 12.30 & 14.00 \\
4 & 14.00 & 15.30 \\
5 & 16.00 & 17.30 \\
6 & 18.30 & 20.00 \\
7 & 20.00 & 21.30 \\
\hline
\end{tabular}

Setiap mata kuliah akan diampu oleh dosen pengajar. Dosen dapat mengampu lebih dari satu mata kuliah di setiap semester pada jam yang berbeda. Tabel 6 adalah contoh dosen mata kuliah.

Tabel 6. Dosen dan mata kuliah

\begin{tabular}{|c|c|c|}
\hline No & Mata kuliah & Dosen pengampu \\
\hline 1 & Bahasa Inggris 2 & $\begin{array}{l}\text { Putri Anggun Sari,.S.Pt.,M.Si, } \\
\text { Arvita Emarilis Intani, S.T., } \\
\text { M.T. }\end{array}$ \\
\hline 2 & Aljabar Linier & $\begin{array}{l}\text { Ikhsan Romli, S.Si., M.Sc, } \\
\text { Ir. Nanang Tedi Kurniadi M.T }\end{array}$ \\
\hline 3 & $\begin{array}{l}\text { Logika } \\
\text { Informatika }\end{array}$ & $\begin{array}{l}\text { Ikhsan Romli, S.Si., M.Sc, } \\
\text { Abdul Halim Anshor S.Kom } \\
\text { M.Kom }\end{array}$ \\
\hline 4 & $\begin{array}{l}\text { Algorithma Dan } \\
\text { Pemrograman } 2\end{array}$ & $\begin{array}{l}\text { Anwar Sucipto, S.Kom, } \\
\text { Edy Widodo, S.Kom. M.Kom, } \\
\text { Ibrahim Syahril, S.Kom }\end{array}$ \\
\hline 5 & $\begin{array}{l}\text { Analisa Dan } \\
\text { Perancangan SI }\end{array}$ & $\begin{array}{l}\text { Agung Nugroho, M.Kom, } \\
\text { Elkin Rilvani, S.Kom, M.M, } \\
\text { Wiyanto, S.Kom, M.Kom }\end{array}$ \\
\hline
\end{tabular}

\subsection{Proses Penjadwalan Algoritma Genetika}

Penyelesaian masalah penjadwalan dengan menerapkan algoritma genetika dengan beberapa tahapan yang akan dilakukan seperti pada gambar 1 .

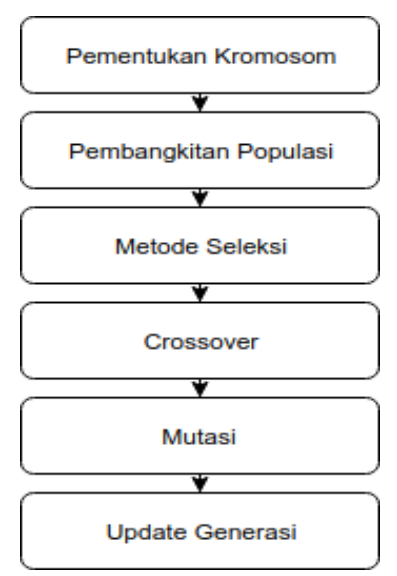

Gambar 1. Proses Algoritma Genetika

\subsection{Constraint}

Constraint merupakan batasan atau syarat khusus yang harus dipenuhi dalam pembuatan jadwal kuliah. Constraint tersebut terbagi menjadi dua jenis, yaitu hard constraint dan soft constraint. Hard constraint merupakan batasan-batasan yang harus dipenuhi dalam penyusunan jadwal, jika tidak terpenuhi maka jadwal tidak dapat digunakan. Hard constraint yang digunakan dalam proses penjadwalan disini adalah sebagai berikut:

1. Dosen tidak boleh mengajar pada dua mata kuliah

2. yang berbeda pada hari dan jam yang sama pada kelas yang berbeda.

3. Dua dosen yang berbeda tidak boleh menempati ruangan yang sama pada hari dan jam yang sama.

4. Beban kerja dosen tidak boleh lebih dari 12 sks per semesternya.

5. Penempatan dosen mengajar harus sesuai dengan bidang ilmu yang dimiliki dan berdasarkan prioritasnya.

6. Selanjutnya adalah soft constraint. Soft constraint merupakan batasan yang boleh tidak dipenuhi, akan tetapi apabila terpenuhi akan menjadi lebih baik. Dalam hal ini, apabila batasan tidak terpenuhi, jadwal tetap bisa digunakan. Soft constraint dalam penelitian ini yang digunakan adalah, waktu atau mata kuliah yang dijadwalkan seusi dengan permintaan dosen yang bersangkutan.

\subsection{Perancangan Aplikasi}

Pada penelitian ini, aplikasi yang digunakan untuk implementasi algoritma genetika menggunakan Java dan database MySQL.

\subsubsection{Perancangan Database.}

Database digunakan untuk menyimpan data awal yang akan digunakan dalam proses penjadwalan mata kuliah untuk memudahkan dalam mengelola data, seperti data dosen, data kelas, data sebaran mata kuliah atau kurikulum, data ruang dan waktu perkuliahan. 


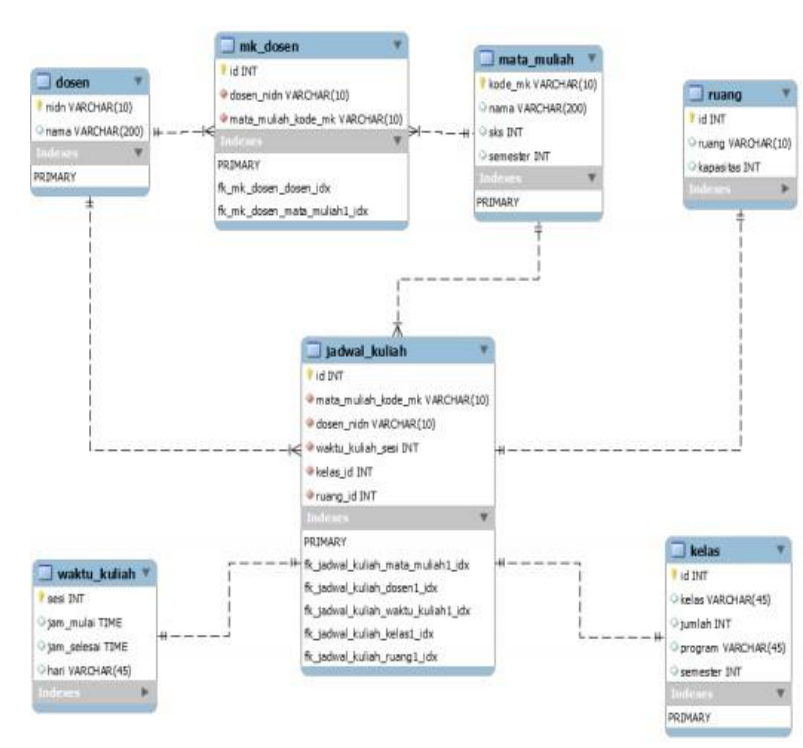

Gambar 2. ERD Penjadwalan Mata kuliah

\subsubsection{Implementasi Algoritma Genetika}

1. Pembentukan kromosom dan populasi Inisialisasi kromosom direpresentasikan dalam bentuk larik atau array yangberisi data yang berkaitan dengan jadwal. Panjang kromosom adalah sebanyak jumlah gen yang ada. Pada kasus ini setiap gen adalah mewakili ruang dan waktu. Setelah kromosom dibentuk, kemudian dilakukan pembuatan populasi awal. Populasi terdiri dari individu-individu pembentuk solusi awal penjadwalan sesuai aturan yang sudah ditetapkan. Pembentukan individu dilakukan dengan beberapa tahapan sebagai berikut:

a. Pilih secara acak dari daftar dosen mata kuliah berdasarkan prioritas dan maksimal jumlah sks dosen.

b. Pilih ruang dan waktu secara acak yang belum pernah digunakan.

2. Fungsi fitness dan seleksi

Selekasi dilakukan dengan memperhatikan nilai fitness dari tiap individu, manakah yang dapat digunakan untuk generasi berikutnya. Seleksi digunakan untuk mendapatkan calon individu terbaik, semakin kecil nilai fitness maka semakin kecil juga kemungkinan individu tersebut terpilih. Banyak cara untuk membagun fungsi fitness. Untuk mendapatkan nilai fitness yang baik diperlukan batasan-batasan yang diberikan sehingga menetukan prioritas batasan yang ada. Dalam kasus penjadwalan batasan tersebut dapat ditentukan berdasarkan nilai constraint.

3. Perkawinan silang

Crossover merupakan bagian dari proses algoritma genetika dengan menyilangkan individu satu dengan individu lainnya. Setiap individu yang memenuhi syarat crossover akan dipotong menjadi dua sesuai dengan kaidah tertentu dan akan menghasilkan dua buah gen baru. Setiap gen tersebut akan dipasangkan dengan gen lain dari individu lainnya.

Proses kawin silang yang pertama dilakukan adalah dengan membuat pasangan individu. Tidak ada aturan khusus dalam membentuk pasangan individu tersebut. Pasangan individu tersebut dapat dibuat dengan pengelompokan jenis individu, misal individu ganjil dengan ganjil, individu genap dengan genap, atau dilakukan secara acak. Setelah dilakukan pemasangan individu, selanjutnya adalah membuat generate crossover rate. Jika memenugi syarat, lakukan silang gen.

4. Mutasi

Mutasi adalah mekanisme proses dalam algoritma genetika untuk mengganti satu atau beberapa gen dari sebuah individu menjadi gen lain yang disusun secara acak. Pola susunan gen pada proses mutasi tersebut tidak ada kaidah tertentu. Karena karakteristik dari algoritma genetika memang disusun secara acak.

Pada proses mutasi membutuhkan syarat mutation rate. Mutation rate adalah angka yang dijadikan prasyarat dalam menetukan individu dapat dilakukan mutasi atau tidak. Nilai dari mutation rate tidak memiliki kaidah tertentu.

\section{Hasil}

Ujicoba dilakukan pada proses pembuatan jadwal perkuliahan pada Prodi Teknik Informatika semester ganjil 2017/2018. Adapun data yang dimasukkan adalah sebagai berikut.

Tabel 7. Data Penjadwalan

\begin{tabular}{lll}
\hline No & Data & Jumlah Data \\
\cline { 1 - 1 } 2 & Dosen & 54 \\
2 & Mata kuliah & 27 \\
3 & Kelas & 23 \\
4 & Ruang & 16 \\
5 & Dosen Pengampu & 65 \\
\hline
\end{tabular}

\subsection{Menentukan dosen pengampu}

Proses penjadwalan dilakukan setelah data master mata kuliah dan dosen tersedia. Selanjutnya adalah menetukan dosen pengampu permata kuliah. Penentuan dosen pengampu tersebut berdasarkan ketentuan yang berlaku pada Program Studi Teknik Informatika STT 
Pelita Bangsa, dan disesuaikan dengan bidang keahlian tiap-tiap dosen.

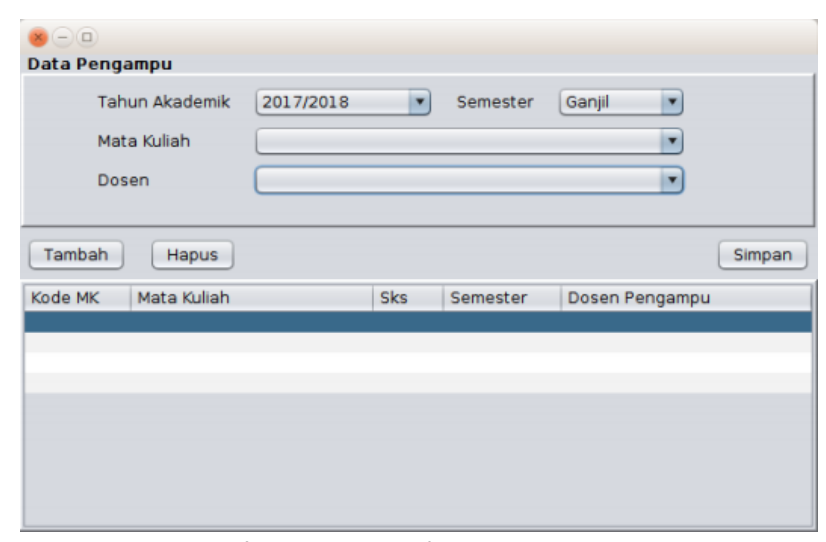

Gambar 3. Input dosen pengampu

\subsection{Proses Penjadwalan}

Setelah data pengampu mata kuliah tersedia pada periode semester tahun ajaran, maka proses penjadwalan dapat dilakukan. Pada proses ini algoritma genetika akan bekerja. Proses optimasi penjadwalan berlangsung pada proses ini. Sebelum memproses penjadwalan, perlu ditentukan jumlah populasi yang akan dibangkitkan untuk mencari nilai optimasi pada proses pejadwalan.

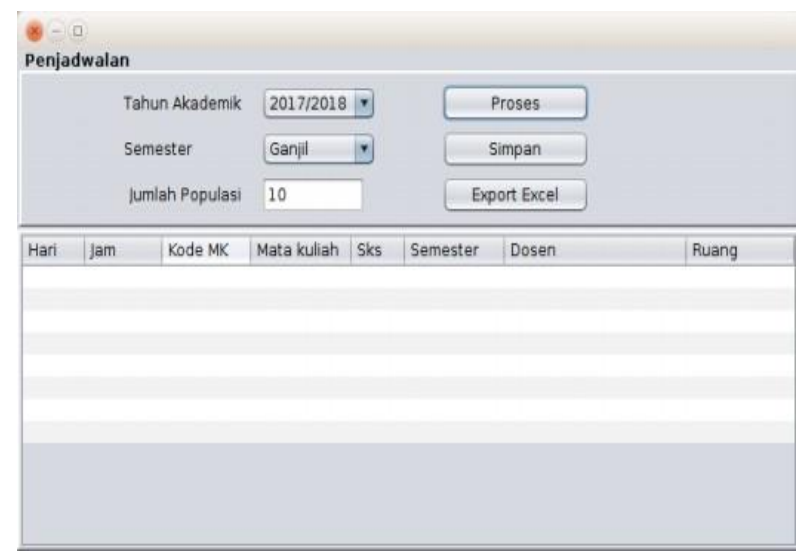

Gambar 4. Proses penjadwalan

Setelah diproses, maka akan ditampilkan hasilnya pada tabel dibawahnya, apabila hasil sudah sesuai data dapat disimpan kedalam database, atau bisa juga di export kedalam bentuk file excel.

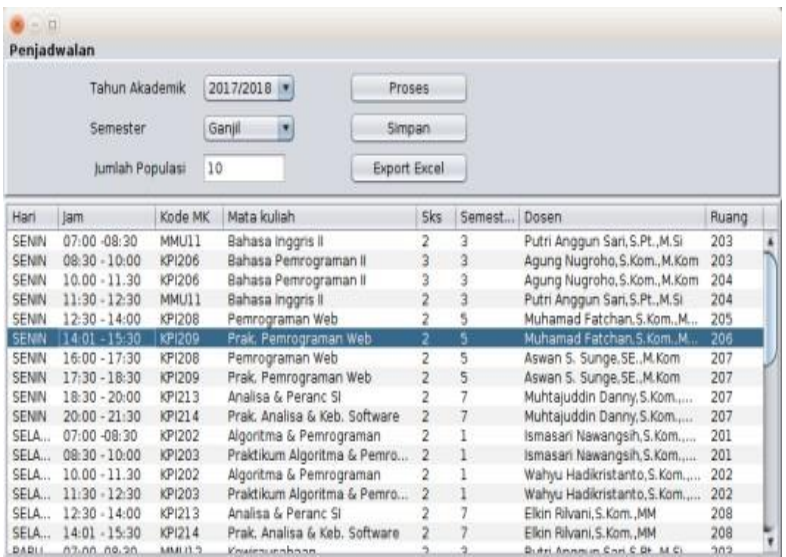

Gambar 7. Hasil penjadwalan

\section{Kesimpulan}

Berdasarkan penelitian yang telah dilakukan, maka diperoleh kesimpulan sebagai berikut:

a. Algoritma genetika cukup efektif dan efisien digunakan untuk pembuatan jadwal kuliah dibandingkan dengan menggunakan excel.

b. Penelitian ini telah berhasil membuat implementasi algoritma genetika kedalam sebuah aplikasi.

\section{Acknowledgement}

Apresiasi dan terima kasih kepada Kementrian Riset, Teknologi dan Pendidikan Tinggi yang telah membiayai kegiatan Penelitian Dosen Pemula (PDP) pada penelitian ini. Terima kasih juga kepada Lembaga Penelitian dan Pengabdian Masyarakat STT Pelita Bangsa yang telah membantu kegiatan ini melalui Kopertis Wilayah IV Jawab Barat.

\section{References}

[1] D. A. R. Wati and Y. A. Rochman, "Model Penjadwalan Matakuliah Secara Otomatis Berbasis Algoritma Particle Swarm Optimization ( PSO )," J. Rekayasa Sist. Ind., vol. 2, no. 1, pp. 22-31, 2013.

[2] W. A. Puspaningrum, A. Djunaidy, and R. A. Vinarti, "Penjadwalan Mata Kuliah Menggunakan Algoritma Genetika di Jurusan Sistem Informasi ITS," J. Tek. Pomits, vol. 2, no. 1, pp. 127-131, 2013.

[3] Y. Marbun, N. Nikentari, and M. Bettiza, "Perbandingan Algoritma Genetika dan Particle Swarm Optimization dalam Optimasi Penjadwalan Matakuliah," Fak. Tek. Umr., pp. 1-7, 2013.

[4] A. Desiani and M. Arhami, Konsep Kecerdasan Buatan. 2006.

[5] W. J. Stevenson, Operations management. 2015.

[6] M. L. Pinedo, Scheduling, Theory, Algorithms, and Systems. Boston, MA: Springer US, 2012.

Program Studi Teknik Informatika

Universitas Prima Indonesia (UNPRI) Medan 
[7] A. Jain, D. Jain, and D. Chande, "Formulation of Genetic Algorithm to Generate Good Quality Course Timetable," Int. J. Innov. ..., vol. 1, no. 3, pp. 248251, 2010. 